\title{
SAFO, OU A BELEZA FRAGMENTÁRIA
}

\author{
ANA PAULA PINTO \\ Faculdade de Filosofia / Braga \\ Universidade Católica Portuguesa
}

\begin{abstract}
RESUMO: Safo e o fragmento 2 L. P.. A irregularidade do processo de transmissão como fundamento para os problemas de delimitação, fixação e interpretação do texto. Análise morfossintáctica, dialectal, semântica e estrutural. Tentativa de interpretação da mensagem poética.
\end{abstract}

PALAVRAS-CHAVE: literatura grega; Safo.

\section{A obra poética de Safo}

A arte de Safo, muito apreciada e lida na Antiguidade (a avaliar pela quantidade de testemunhos que dela nos transmitiram os autores antigos), atravessou os tempos particularmente fragmentada: dela nos chegaram, com raros poemas completos, múltiplos fragmentos, resplandecentes de encanto, de espontaneidade, de frescura, como estilhaços de cristal ou joalharia fina, a emergir, frementes de luz, numa paisagem de ruínas e destroços. Apesar dessa castradora mutilação, que inibe o leitor de captar o todo - num juízo definitivo e integral - a qualidade poética da obra tem o estranho condão de oferecer a quem a lê a capacidade de ultrapassar as incontornáveis dificuldades supostas na sua transmissão. Na verdade, sem que consigamos efectivamente perceber como, a musicalidade dos seus termos, a qualidade excepcionalmente transparente e luminosa das suas imagens, a fluidez do seu ritmo, o virtuosismo das suas palavras, e essa capacidade quase mágica de transmitir uma impressão profundamente tocante acerca do absolutamente inefável, fornecem ao leitor a chave para intuir nos pequenos fragmentos que restam o significado da criação poética integral. Na verdade, da obra poética de Safo se pode justamente dizer que não só ultrapassa os limites do tempo, mas vive à margem do próprio tempo, sempre presente e viva em cada época. 


\section{O óstracon Ptolomaico: os problemas da transmissão}

O fragmento 2 L.P de Safo já vinha parcialmente transmitido, enquanto representante da arte sáfica, desde a Antiguidade. Na verdade, Hermógenes (Пદpi i $\delta \varepsilon \hat{\omega} v, 2.4$, p. 331-32 Rabe) citava os versos 5-8, com algumas variantes e lacunas $^{1}$, a propósito das possibilidades do estilo descritivo, e dos prazeres que ele proporciona:

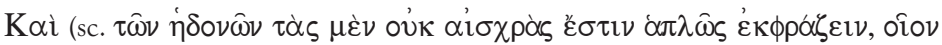

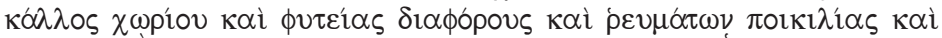

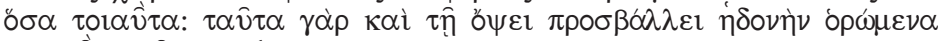

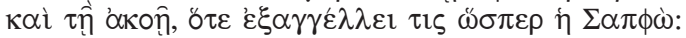

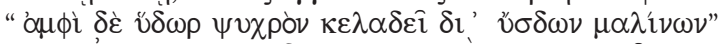

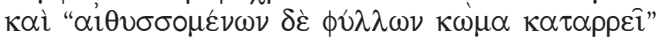

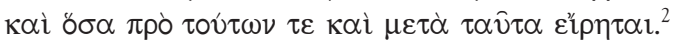

Dos vv. 13-16, por outro, deixou testemunho Ateneu (11, 463 c-e), expondo uma erudita improvisação discursiva do deipnosofista Plutarco, que, apresentando-se num banquete como orador, disserta sobre os costumes dos Gregos e dos Bárbaros relativamente à bebida; depois de citar Xenofonte, Anacreonte, e Ílon de Quios, e lembrar como Alexis de Tarento defendia que quem brinda à alegria e a Afrodite sai desta vida como se abandonasse a mais bela festa, reproduz oportunamente, na sequência da alusão à bebida, aos prazeres e a Afrodite, a composição de Safo:

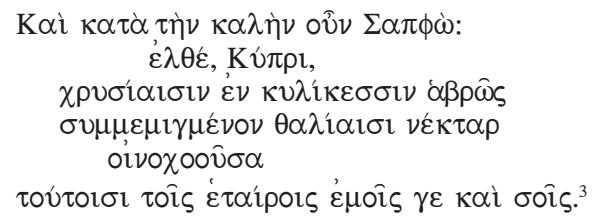

1 A edição de Bergk (BERGK: 18824) reconhece respectivamente como fragmentos 4 e 5 o conjunto dos versos 5-6 e 7-8; Diehl (1936) apresenta, por sua vez, como o fragmento 5 o conjunto dos versos $5-8$.

2 "É possível descrever em termos simples prazeres que não são ordinários, como a beleza de um lugar, a variedade das plantas, e a diversidade dos cursos de água, e coisas semelhantes. Estas realidades trazem prazer ao olhar, quando se vêem, e ao ouvido, quando se escutam. Assim (dizia) Safo: "E ali, uma água fresca murmura através dos ramos das macieiras" e "das folhas trémulas escorre um sono de encantamento", e tudo isto é dito antes e a propósito disto".

3 "E, como diz a bela Safo: "Vem, tu, ó Cípria,/ Vertendo graciosamente em taças de oiro /o néctar misturado para as festividades", para estes meus e teus amigos." 
Além disso, foram ainda mencionados em antigas gramáticas, pelas suas peculiaridades dialectais eólicas, vários termos isolados do contexto.

Exceptuando estas reduzidas citações, o poema permaneceu desconhecido, enquanto unidade poética e temática, durante séculos, até que, em 1937, uma especialista em Papirologia da Universidade de Florença, Medea Norsa ${ }^{4}$, divulgou, num artigo dos Annali della R. Scuola Normale Superiore Universitaria di Pisa ${ }^{5}$, a sua mais recente aquisição ao serviço ao serviço da Società Italiana per la Ricerca dei Papiri Greci e Latini in Egitto: um inesperado óstracon ptolomaico (séc. II a.C.). O documento, na superfície fragmentária e rugosa de um vaso de cerâmica, do tamanho aproximado de uma mão de adulto, e com o canto superior direito algo mutilado, contém uma longa inscrição de quase duas dezenas de versos, que reúne numa mesma unidade poética os dois testemunhos transmitidos separadamente desde a Antiguidade:

\begin{tabular}{|c|c|}
\hline 1a & $\rho \alpha \nu \circ \theta \varepsilon v \kappa \alpha \tau i \circ v[$ \\
\hline 1 & $\delta \varepsilon v \rho v \mu \mu \varepsilon \kappa \rho \eta \tau \alpha \sigma \pi[$ \\
\hline & 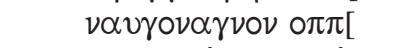 \\
\hline 3 & $\chi \alpha \rho \imath \varepsilon \nu \mu \varepsilon v \alpha \lambda \sigma \circ \sigma \mu \alpha \lambda \mathrm{i}[$ \\
\hline & $\omega \mu \circ \imath \delta \varepsilon \mu \imath \theta v \mu \imath \alpha \mu \varepsilon v 01[$ \\
\hline & $\alpha \nu \omega \tau \omega \varepsilon v \tau v \delta \omega \rho \psi v \chi \rho \circ[$ \\
\hline
\end{tabular}

4 Medea Norsa (Trieste,1877 / Florença, 1952) formou-se em Literatura Grega no Istituto di Studi Superiori di Firenze, e trabalhou no Gabinete de Estudos Papirológicos da mesma instituição, dirigido pelo seu antigo professor de Literatura Grega, Girolamo Vitelli. Substituiu posteriormente o mestre na direcção do Instituto Papirológico da Universidade de Florença, onde desenvolveu, paralela à docência (de Filologia Antiga e Papirologia), uma proficiente actividade científica de decifração e publicação de papiros, que ela mesma, ao serviço da Società Italiana per la Ricerca dei Papiri Greci e Latini in Egitto, adquiria, a partir de recorrentes viagens ao Egipto. Manteve contactos com alguns dos mais importantes filólogos e investigadores da Europa, e foi membro de algumas instituições de prestígio internacional, como a Pontificia Accademia Romana di Archeologia, o Instituto Arqueológico Alemão, a Association Internationale de Papyrologues de Bruxelles, e a Bayerische Akademie do Mónaco. Perseguida no período da segunda Guerra mundial pelas leis raciais, por ser de origem hebreia, acabou por ser marginalizada na sua actividade académica, e depois de um prolongado período de doença, morreu em Florença em 1952.

5 NORSA (1937). O artigo continha uma reprodução fotográfica. O fragmento, conservado na Biblioteca Laurenziana, em Florença, tem-se deteriorado a tal nível que chega a ser mais legível nas reproduções fotográficas entretanto feitas, nomeadamente a de K. MATTHIESSEN (1957). 


\begin{tabular}{|c|c|}
\hline 5 & $\lambda \alpha \tau \imath \delta 1 \delta v \sigma \chi \omega \nu \mu \alpha \lambda \imath \alpha \nu[$ \\
\hline & 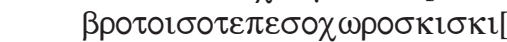 \\
\hline & $\alpha \sigma \tau \alpha \imath \theta v \sigma \sigma o \mu \varepsilon v \omega \nu \delta \varepsilon \phi v \lambda \lambda \omega \nu[$ \\
\hline & $\kappa \omega \mu \alpha \kappa \alpha \tau \alpha \gamma \rho i o v \varepsilon \nu \delta \varepsilon \lambda \varepsilon 1 \mu \omega \nu[$ \\
\hline & $\imath \pi \pi \circ \beta \circ \tau \circ \sigma \tau \varepsilon \theta \alpha \lambda \varepsilon \tau \omega \tau \quad \operatorname{l\rho } v[$ \\
\hline & $\nu 0 \imath \sigma \alpha \nu \theta \varepsilon \sigma i v \alpha l \alpha \alpha \imath \eta \tau \alpha l \mu \varepsilon \lambda \lambda_{1}[$ \\
\hline & $\chi \alpha \pi \nu \varepsilon \circ 1 \sigma \iota v \varepsilon \nu \theta \alpha \delta \eta \sigma v \sigma \varepsilon \mu[$ \\
\hline & $\varepsilon \lambda \circ 1 \sigma \alpha \kappa v \pi \rho \imath \chi \rho v \sigma \varepsilon \alpha 1 \sigma \varepsilon v \kappa v[$ \\
\hline & $\lambda \iota \kappa \varepsilon \sigma \sigma i v \alpha \kappa \rho \omega \sigma \quad \mu \varepsilon \mathrm{l}[$ \\
\hline & $\chi \mu \varepsilon v \circ \nu \theta \alpha \lambda \lambda_{1} \alpha 1 \sigma o v[$ \\
\hline & 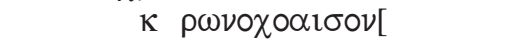 \\
\hline
\end{tabular}

A comparação do achado recente com os testemunhos das antigas gramáticas - e o tom poético sem paralelo - não deixaram margem a dúvidas quanto à autoria do poema.

A publicação de um novo carme de Safo, um dos autores antigos mais cobiçados pelos papirólogos, alvoroçou por completo os meios académicos, a crítica literária e os apreciadores de poesia, e nem sequer deixou indiferentes os grandes jornais europeus ${ }^{6}$.

E apesar de o óstracon se ter tornado, desde a sua primeira publicação, o centro de uma intensa e entusiástica polémica, que sem dúvida concorreu para esclarecer alguns dos problemas de detalhe, a investigação filológica tem de reconhecer, no entanto, que a discussão de algumas das questões básicas (como os da datação e autoria da inscrição, limites e fixação do texto) não produziu ainda uma resposta única, cabal, e definitiva, que permita interpretar pacificamente o mistério do seu conteúdo.

6 Um novo carme de Safo era uma notícia sensacional até para os Jornais. Il populo d'Italia apressou-se a apresentar a 14 de Julho de 1937, um artigo ("La scoperta di una nuova ode di Saffo,") da autoria de Gofredo Coppola. O The Times relançou também com grande entusiasmo em Inglaterra a notícia, a 16 de Julho, por meio do seu correspondente de Milão, Mario Borsa: "On a fragment of pottery of the 2nd Century B.C. discovered in Egypt by Signor Evaristo Breccia, an Italian excavator, Signora Medea Norsa has found inscribed 18 lines of an ode by Sappho, of wich up to now only some fragmentary quotations were known. Such pieces of pottery were generally used for receipts, unimportant notes, and other common purposes, but it is known that in the ancient schools the boys occasionally made use of such material instead of waxed tablets or papyri. This, however is the first fragment of pottery known to bear Sappho's lines, and is the oldest document we have of an ode of Sappho". 


\subsection{Datação e autoria da inscrição}

tipo de escrita utilizado na inscrição, por um lado, primitivamente identificado como pertencendo ao século II a.C., parece ser tendencialmente atribuído, pela crítica mais recente (vd. PAGE: 1955, p. 35), ao século III a.C.. Por outro, a contradição evidenciada entre a qualidade e fluência dessa mesma técnica de escrita, num material tão irregular, e o medíocre conhecimento linguístico que ela veicula (particularmente nas formas de cariz dialectal, reproduzidas com numerosíssimos erros), empresta fundamento ao debate sobre a identidade do copista. Alguns autores aceitam a hipótese de a inscrição do texto sáfico na superfície convexa do recipiente ser produto de um exercício escolar de ditado, da responsabilidade de um estudante que, dotado na arte de reprodução gráfica, não manifestaria iguais talentos a outros níveis literários (Setti, 1943; Martin, 1947; Lanata, 1959). Outros crêem ter-se tratado de um estrangeiro culto (provavelmente egípcio), familiarizado com os tesouros literários da cultura grega que, conhecendo reduzidamente as leis da ortografia e as particularidades do dialecto eólico, se teria deixado fascinar pelo valor incontestável dos versos (Gallavoti, 1942; Siegmann, 1941). Sem se deter em maiores suposições, Page (PAGE: 1955, p. 35, n. 1) considera mais provável que o óstracon fosse obra de um estrangeiro não familiarizado com as complexas particularidades do dialecto eólico, do que o produto de uma escola ptolomaica onde se ditassem poemas de Safo a jovens ignorantes e particularmente negligentes.

\subsection{Limites e fixação do texto}

O inusual processo de transmissão a que foi sujeita a mesma composição justifica, além disso, muitas das dúvidas que se colocam acerca da delimitação e fixação do texto sáfico.

Embora a inscrição em fragmentos de cerâmica não seja um achado insólito (uma vez que a arqueologia tem trazido à luz inúmeros casos de ostraka deste tipo contendo pequenas notas, receituários, ou listas administrativas e documentos de reduzida importância), ele configura-se como absolutamente excepcional na história da literatura antiga. A composição poética surge-nos, aliás, como o único texto lírico- e mesmo literário - do Ocidente a chegar até nós gravado num óstracon. A natureza paleográfica do documento justifica, além disso, outros graus de dificuldade, uma vez que o texto poético se apresenta sem distinção nítida entre versos e ou estrofes, e marcado de inúmeras corrupções. Por fim, a comparação com os testemunhos dos antigos gramáticos (particularmente o de Ateneu) sugerem, 
ainda, a possibilidade de que a unidade total do poema, aliás insuspeita durante séculos, continue a furtar-se à consciência dos homens.

Desde a publicação do óstracon, foram, por isso, sopesadas e defendidas quatro possibilidades fundamentais de delimitação do poema, que atribuem à composição poética original a variável extensão de quatro, cinco ou seis estrofes sáficas? Alguns autores (como Rivier, e Gallavoti) defendem que, começando no primeiro verso completo, a composição terminaria, de igual modo, no último verso completo documentado no fragmento de cerâmica, isto é, na quarta estrofe; as primeiras palavras documentadas no óstracon pertenceriam, portanto, a um outro poema. Outros investigadores (e.g., Pfeiffer, Theander, Kaibel, e, de forma hesitante, Page) pretendem que o poema começaria no primeiro verso completo (correspondente à segunda linha do óstracon) e terminaria numa quinta estrofe posterior, não documentada no achado, mas sugerida pelo testemunho de Ateneu, que acrescenta ao

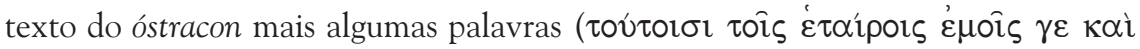
$\sigma o i \varsigma)^{8}$; as primeiras palavras gravadas no óstracon continuam a ser interpretadas como pertencendo a outro poema. Há também quem confira particular autoridade à transmissão do óstracon, e conclua que o poema começaria com uma primeira estrofe muito danificada, apenas parcialmente documentada na primeira linha do achado (que corresponderia ao final da estrofe introdutória), e terminaria numa quinta estrofe completa, com as últimas palavras inscritas no fragmento de barro; ao poema, reproduzido como unidade poética no óstracon, faltariam apenas os versos iniciais da primeira, e poucas palavras da penúltima estrofe (Norsa, 1937; Schubart, 1938; Turyn, 1942; Lasserre, 1948; Schadewaldt, 1950; Fränkel, 1962; Mathiessen, 1957; Lanata, 1959; Treu, 1954; Kirkwood, 1974). A última hipótese apontada, mas nunca verdadeiramente defendida por nenhum investigador (cfr. Page, 1955, pp. 34 sqq.), admite que a composição começaria numa primeira estrofe apenas parcialmente conservada no óstracon, e terminaria numa sexta estrofe sugerida pelo testemunho de Ateneu.

Embora o desenvolvimento da polémica, propondo conjecturas tão divergentes e artificiosas, comprove que se não pode facilmente chegar a uma conclusão segura, a análise do documento pode fornecer algumas pistas que permitam determinar critérios para a fixação do início e do final do texto.

7 Para o esclarecimento de posições, e a correspondente fundamentação bibliográfica, vd. Burnett , 1983, pp. 260 sqq..

8 Já anteriormente Bergk (18824) e Turyn (1929) interpretavam como da autoria de Safo as palavras referidas por Ateneu. 
Uma vez que o achado paleográfico do óstracon conserva aparentemente a sua extensão original, apenas lhe faltando parte do canto superior direito, as hipóteses (primeira e segunda) que propõem a separação da primeira linha escrita (porque pertencente a outra composição) implicam a suposição - muito difícil de sustentar - de que o copista usaria uma série de fragmentos de recipientes, continuando o seu acto de cópia de uns para outros, motivado talvez pelo desejo de constituir uma antologia poética. Além disso, a tipologia reconhecível do poema (ao que parece, um poema de natureza invocatória, como veremos adiante) implica a necessidade de uma prévia invocação (mais ou menos formal) da divindade. $\mathrm{O}$ facto de as primeiras letras do óstracon documentarem erros dialectais e serem metricamente insustentáveis é também argumento inconclusivo contra a sua integração no todo, uma vez que dos mesmos erros enferma toda a inscrição. Tudo parece apontar, pois, para a probabilidade de o início do poema se dar pouco antes das primeiras duas palavras conservadas no óstracon, que pertenceriam então ao final da primeira estrofe perdida?.

Por outro lado, a hipótese de uma eventual continuidade do poema numa estrofe perdida (sustentada pelas segunda e quarta posições) embate também numa dificuldade de natureza epigráfica: como Giulia Lanata (LANATA:1959) refere, o fragmento de barro apresenta, depois da última linha transmitida, um espaço livre (e inaproveitado) que é pelo menos duas vezes superior ao que regularmente permeia entre duas linhas das conservadas. A citação de Ateneu, que tem servido de fundamentação para a mesma hipótese, não parece ter, aliás, valor comprovativo, uma vez que se pode interpretar - mais do que como a paráfrase da composição sáfica- como a reprodução do final da improvisação erudita de Plutarco aos com-

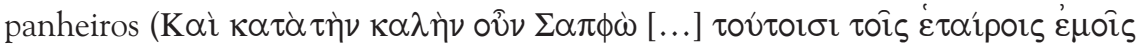
$\left.\gamma \varepsilon \kappa \propto i \sigma o i \varsigma \varsigma^{10}\right)^{10}$ A analogia com outros poemas do mesmo tipo revelará, de resto, que a última estrofe conservada corresponde perfeitamente ao final bem conseguido e estruturado de um poema clético (invocatório).

9 Theiler e Von der Mühll (1946) chegaram mesmo ao ponto de propor a reconstrução da primeira estância desta forma:

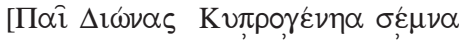

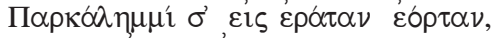

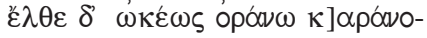

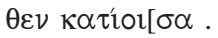

10 Saake (1971, p. 90) nota acertadamente que o último verso, com as suas formas nominais masculinas, não se enquadra facilmente no âmbito contextual das composições poéticas de Safo, onde se não poderiam senão compreender as correspondentes femininas. 


\subsection{Possíveis interpretações do texto}

Com base nesta argumentação, propusemos nós então para análise formal uma versão do texto que se aproxima, nos seus limites extremos, da transmitida pelo achado epigráfico. Na tentativa de esclarecer os imensos problemas de exegese colocados pelo texto inscrito no óstracon (como vimos, excepcionalmente marcado por erros e ambiguidades de vária natureza), tomaremos naturalmente por base uma das edições consagradas (PAGE, 1968), à qual acrescentaremos algumas das mais notáveis variantes propostas por outras edições. A partir da análise interna (morfossintáctica, semântica, dialectal e estrutural) procuraremos então abrir perspectivas para a interpretação da mensagem poética de Safo.

\begin{tabular}{|c|c|}
\hline PAGE & Texto \\
\hline 1a & 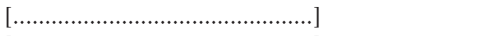 \\
\hline $1 b$ & 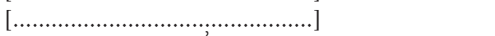 \\
\hline $1 \mathrm{c}$ & 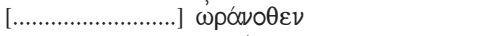 \\
\hline $1 \mathrm{~d}$ & 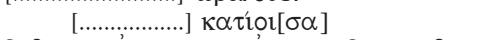 \\
\hline 1 & 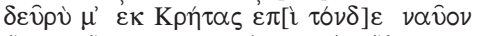 \\
\hline 2 & 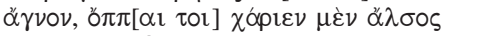 \\
\hline$J$ & 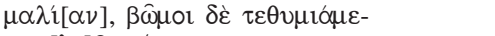 \\
\hline 4 & vor $[\lambda l] \beta \alpha \nu \omega \tau \omega l$ \\
\hline 5 & 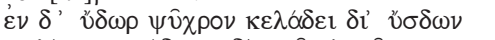 \\
\hline 6 & 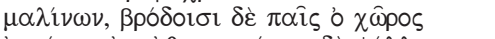 \\
\hline 7 & 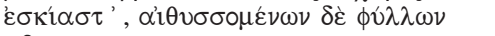 \\
\hline 8 & $\kappa \hat{\omega} \mu \alpha \kappa \alpha \tau \varepsilon \rho \rho \varepsilon \imath$. \\
\hline 9 & 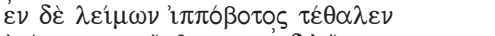 \\
\hline 10 & 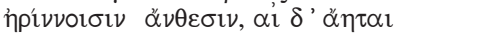 \\
\hline 11 & 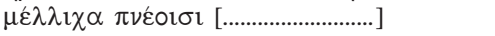 \\
\hline 12 & 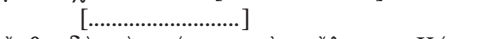 \\
\hline 13 & 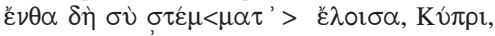 \\
\hline 14 & 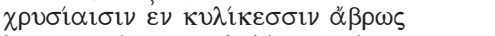 \\
\hline 15 & 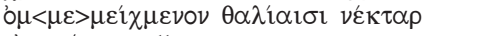 \\
\hline 16 & 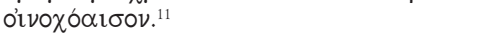 \\
\hline
\end{tabular}

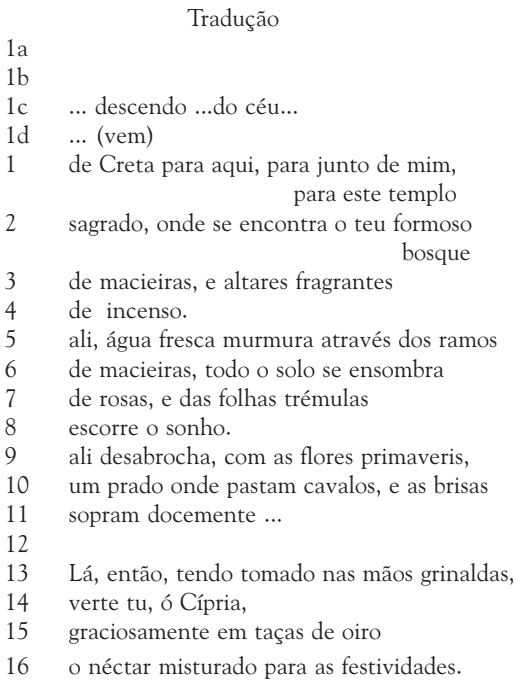

11 Eis algumas das mais notáveis variantes propostas por outras edições:

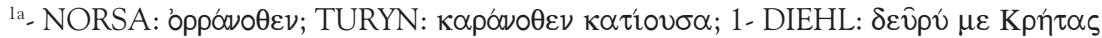

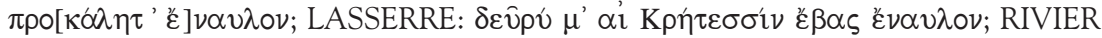

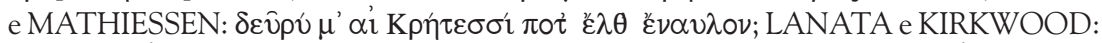

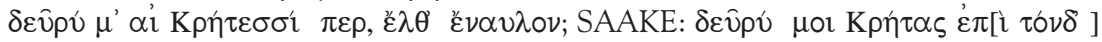

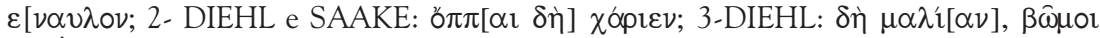

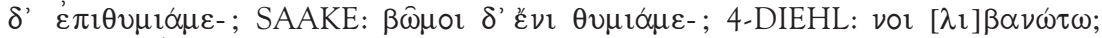

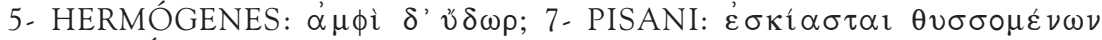

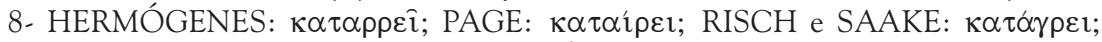

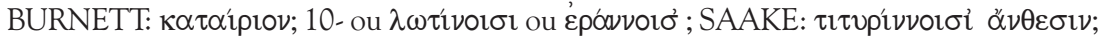

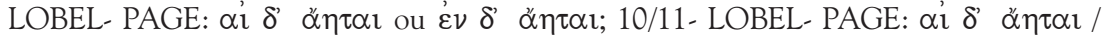


Como acabamos de verificar pela leitura e tradução, o motivo da composição poética é uma prece a Afrodite, para que se apresente num local de culto, perante o sujeito poético interpelante. A invocação da divindade, subentendida no primeiro momento, e formalmente retomada na última estrofe do poema, empresta fundamento à descrição do local, que parece ser, na verdade, elemento poético nuclear na estruturação do poema; para ele, aliás, remetem os começos das

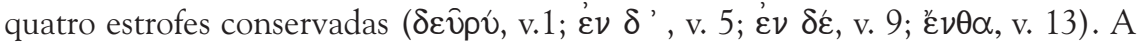
dramatização progressiva dos aspectos da natureza propiciará, no final da composição, a epifania da divindade.

Pela seriação dos vários elementos da natureza, suportes simbólicos de uma intenção poética metaforizada, este pode associar-se tematicamente a outros poemas menores de Safo: assim, os fragmentos 34 LP (com a simbologia profunda da lua resplandecendo entre as estrelas), o 47 LP (comparando o ímpeto do desejo com um vento descendo a montanha), 104a e 104b LP. (que alude aos contraditórios movimentos impostos à natureza pelo sombrear do dia), 105a e 105c L.P. (a conotar respectivamente a castidade da maçã intocada no ramo mais alto da macieira e a fragilidade do jacinto colhido e desprezado pelo chão) e 130 LP (que associa a violência do desejo a um animal selvagem). Além disso, o tema - o apelo de um mortal à epifania divina - comum noutros textos da Antiguidade, recorre em vários poemas de Safo (nomeadamente o fr. $1 \mathrm{LP}$ ), o que permite estabelecer, a nível estrutural, pontos de relação.

\subsection{Comentário lexical (morfossintáctico, dialectal e semântico) do poema}

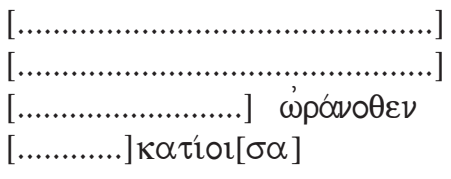

vv. 1c-1d: A expressão proposta como correcção à versão mutilada do óstracon ( $\rho \vee v 0 \theta \varepsilon v \kappa \alpha \tau i o v)$ foi muito contestada por não documentar, na suposta

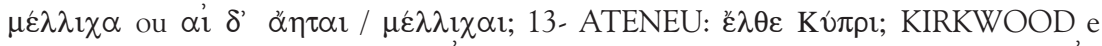

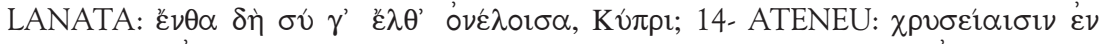

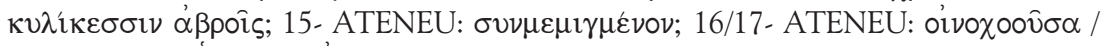

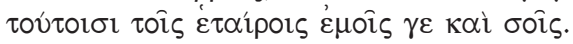




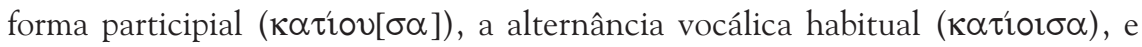
por se não adequar à métrica da estrofe sáfica, cujo último verso (o quarto) deveria corresponder à estruturação prosódica de um adónico ${ }^{12}$.

A reconstituição de uma primeira estrofe perdida, proposta por alguns editores - baseada na suposição de que os mesmos termos obscuros ( $\propto$ $\alpha \circ \theta \varepsilon v \kappa \alpha \tau 10 v$ ) corresponderiam a uma paráfrase imperfeita, feita de memória, do texto original resolveria ambos os problemas. Na verdade, ela permitiria não só deslocar a forma adverbial para a parte final do terceiro verso da estrofe perdida, e o particípio, corrigido e completado, para o final do quarto, mas ainda forneceria os elementos morfossintácticos capazes de configurar (ainda que parcialmente) a invocação e prece formais estruturalmente prováveis e necessárias: o eu poético apresentar-seia, assim a rogar à deusa que, descendo dos céus, se apresentasse no local. Para esta

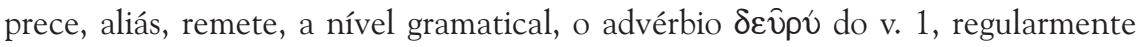
construído com imperativo, e a estruturação circular da composição, que retomará no v.13 a mesma noção da epifania desejada.

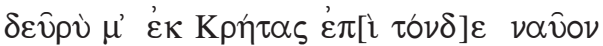

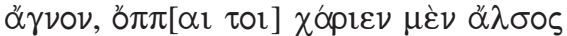

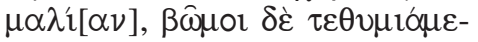 vor $[\lambda \mathrm{r}] \beta \alpha \nu \omega \tau \omega \mathrm{l}$.}

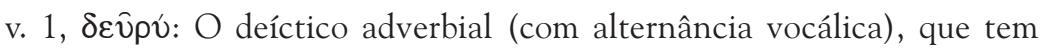
carácter invocatório, resumiria, como se disse atrás, o movimento descendente da primeira estrofe, orientando a pretendida epifania para as proximidades do eu poético. A este ponto local fixo se referirão todas as ideias espaciais da descrição que se segue (vv.1-12), acrescentadas ou hipotacticamente (v.2), ou paratacticamente (vv. 3 sqq.). Este movimento de aproximação, sugerido pelos traços da paisagem,

$12 \bigcirc$ frag. 2 L. P. corresponde ao esquema métrico da estrofe sáfica, sobre o qual se estruturariam todas as composições sáficas organizadas pelos alexandrinos no Livro Primeiro. Esta estrofe sáfica é composta de quatro versos: os três primeiros obedecem à estrutura métrica constante de

$--x|-\cdots-|---$

sendo o quarto verso um adónico: _ $\cdots \_$_

Assim, a estrofe sáfica pode metricamente representar-se como:

$--x \mid-\cdots-1--$

$-\sim x|-\cdots-|--$

$-\sim x|-\cdots-|--$

$-\cdots--$. 
processar-se-á por uma gradual restrição dos espaços (do elemento cósmico da divindade, os céus, para o plano humano do eu poético, referenciado como Creta, e depois, sucessivamente, como o bosque, e seus elementos constituintes menores).

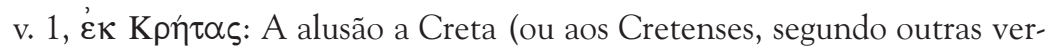
sões propostas) conota a importância da ilha (ou do povo) no contexto específico do culto a Afrodite, para a qual apontariam, aliás, os testemunhos de Diodoro Sículo e de Hesíquio ${ }^{13}$. A alusão a uma primitiva epifania aos Cretenses apresentar-se-ia, além disso, estruturalmente analógica à primeira anterior epifania da deusa documentada no fr. 1.

v. 1, vav̂ov: O primeiro elemento da paisagem- descrita não por si mesma,

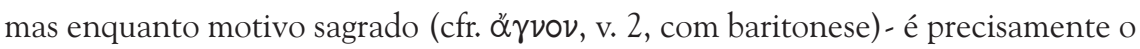
templo (veja-se na forma proposta, além da baritonese, a presença do antigo digama do radical vav-, que, em posição intervocálica, se grafa como - v- ).

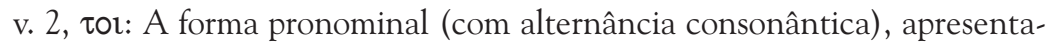
se como dativo de posse ("onde [fica] o teu antro/bosque").

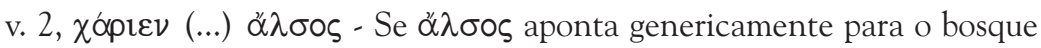
habitado por divindades, $\chi$ ópııv sugere já um fenómeno do círculo de Afrodite e seu culto (Xópıs pode, na verdade, regularmente representar um dom da Cípria).

v. 3, $\mu \alpha \lambda \dot{i} \alpha \nu$ : Trata-se do genitivo plural eólico de $\mu \eta \lambda \dot{\varepsilon} \alpha$, macieira (com dupla alternância vocálica). Associa-se-lhe, no v. 6, o adjectivo derivado $\mu$ ó̀ ıvos. O motivo das maçãs e macieiras configura também simbolicamente a imagem de Afrodite (à qual andavam tradicionalmente associadas umas e outras).

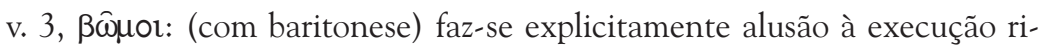
tual do culto, nos altares donde sobem para o ar nuvens de incenso; note-se, no entanto, que não há nenhuma alusão a sacerdote ou sacerdotisa (pois isso con-

13 O historiador refere (Diod. Sic., V, 77, 4-5) que os Cretenses reclamavam para si a honra de terem sido os primeiros a prestar culto a Afrodite; o lexicógrafo, por sua vez, aponta (Hes., s.v. $[\mathrm{A} \nu \theta \varepsilon \imath \alpha)$ que em Cnossos ela era adorada sob o título de Anteia. 
trariaria não só a função essencialmente descritiva desta parte do poema, como também, vê-lo-emos, a atitude voluntariamente acausal e discreta do eu poético, que procura, no poema, apagar da paisagem mística todos os vestígios da (sua) presença humana.

v. 4, $\lambda 1 \beta \alpha \nu \omega \dot{\tau} \omega \mathrm{t}$ : O termo inscrito no óstracon $(\lambda 1 \beta \alpha \nu \omega \tau \omega)$ pode interpretar-se como um genitivo eólico ( $\lambda \iota \beta \alpha \nu \omega ́ \tau \omega$, com alternância vocálica e baritonese, por $(\lambda\lrcorner \beta \alpha \nu \omega \tau 0 \hat{v})$, ou um dativo; ambas as construções são sintacticamente aceitáveis com o verbo $\theta u \mu t a ́ c \omega$ (genitivo de matéria: exalar fumo de incenso; ou dativo de meio: fumegar com incenso); as mais antigas referências ao incenso encontramse precisamente aqui e no fr. $44,30^{14}$. Semanticamente, o termo permite retomar o fenómeno de movimento sugerido nos vv.1c/1d (que será subitamente sustido no momento estático da descrição, vv. 1-3): ele referencia, portanto, um movimento de elevação (do incenso, materialidade da esfera humana, para a esfera cósmica da divindade) que se opõe à anterior descensio da deusa (suposta na primeira estrofe perdida).

vv. 1-4 (comentário semântico): Na descrição que se propõe, a poetisa compraz-se no jogo de opostos: aos contraditórios movimentos de afastamento e

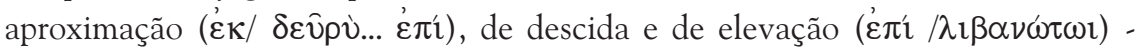
sugeridos não através de formas verbais, elididas, mas do advérbio, das preposições e mesmo do substantivo - ela opõe o estatismo das coisas (" $\pi \pi \alpha \iota$ ). A magia da paisagem implica um apelo sinestésico aos sentidos da visão e do olfacto. O quadro descrito, por meio de graduais restrições do espaço, apresenta uma componente religiosa, que se sustenta de constantes referências, directas ou indirectas, à divindade. Como vimos, através de uma atitude de discrição (que comporta, aliás, uma certa acausalidade dos fenómenos humanos), o sujeito poético coloca a tónica no elemento divino, trazendo para o primeiro plano a espacialidade do culto na sua referência imanente à divindade, para a qual parece dirigir-se pouco a pouco a (sua) expectativa poética.

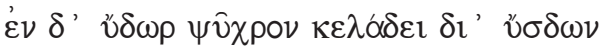

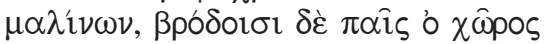

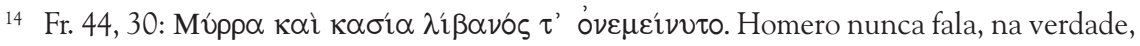
deste elemento, que deve ter sido introduzido na Grécia pelos comerciantes fenícios, cerca de 700 a. C.; para mais detalhes, vd. Page, 1955, p. 36. 


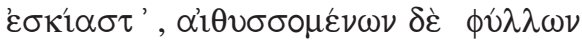
$\kappa \omega \hat{\mu} \alpha \kappa \alpha \tau \dot{\varepsilon} \rho p \varepsilon l$.

v. 5, 'v $\delta$ ' (ali): A locução adverbial manifesta uma enigmática mudança de perspectiva local (cfr. no v. 1, $\delta \varepsilon \hat{p}$ v̀, para aqui), que parece traduzir, como já referimos, a intenção poética de distanciamento, ou atenuação da presença humana no espaço da imanência divina.

v. 5, $\kappa \varepsilon \lambda \alpha \dot{\alpha} \delta \varepsilon$ : Homero tinha já usado o verbo $\kappa \varepsilon \lambda \alpha ́ \alpha \omega$ para a água (Il.

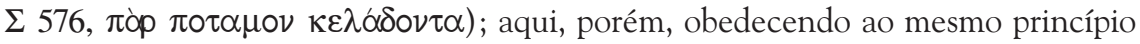
de acausalidade dos fenómenos, não se faz qualquer referência à origem da água fresca que escorre pelos ramos das macieiras: ou se trata de uma provável queda de água, ou simplesmente de uma referência metonímica ao som que se escuta através dos ramos.

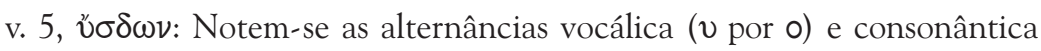
$(\sigma \delta$ por $\zeta$ ); ambos os elementos da natureza referenciados (a água e os ramos da macieira) andam tradicionalmente associados ao culto ritual de Afrodite.

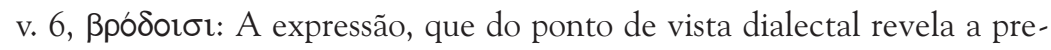
sença do antigo digama (grafado regularmente como $\beta$ em início de palavra), representa sintacticamente o complemento circunstancial de meio. Relevante, no contexto da prece a Afrodite, continua a ser o facto de as rosas (como as maçãs e a água) serem insígnias da deusa ${ }^{15}$, aludindo à sua imanência na topografia.

v. 7, $\alpha \hat{\imath} \theta v \sigma \sigma o \mu \varepsilon \dot{\varepsilon} \omega \nu$ "agitando-se": É o primeiro uso deste verbo tão raro, posteriormente utilizado por Píndaro (Ol. X, 73; Pit. I, 87), Baquílides (fr. 208), Sófocles (fr. 542) e Eurípides (Tr. 344); talvez pudesse, para resolver a dificuldade de um verbo intransitivo no verso seguinte, considerar-se absoluta (particípio absoluto) a expressão $\alpha \dot{\imath} \theta v \sigma \sigma o \mu \dot{\varepsilon} v \omega \nu \delta \dot{\varepsilon}$ фú $\lambda \lambda \omega \nu$.

15 A tradição poética dizia que as rosas brotavam na Primavera, durante o período húmido dos aguaceiros, debaixo da sedução dos passos da deusa; e que, no seu culto, em Afrodísia, lhe eram particularmente consagradas mirra e rosas, muitas vezes entrelaçadas em coroas; para uma análise detalhada do tema, vd. Burnett, A. P. : 1983, p. 263, n. 89. 


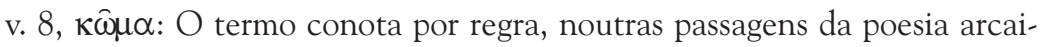
$\mathrm{ca}^{16}$, e mesmo em textos do âmbito da medicina onde ocorre (Hipócrates, Epid. III, 1; III, 6), não simplesmente o sono natural, ou sono profundo, mas sempre sono induzido pelo encantamento ou quaisquer outros meios sobrenaturais; aqui, o agente directo dessa sonolência parece ser directamente o murmúrio das águas e o sussurrar das folhas (embora se possa considerar implicitamente que o sono representa uma possessão divina, ou transe encantatório, produzido pelo poder imanente da divindade na natureza circundante).

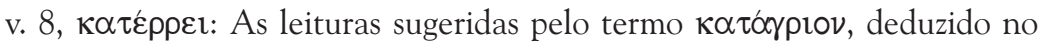

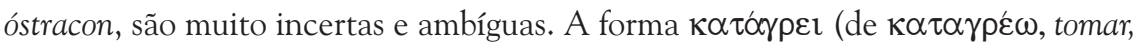
surpreender), a mais próxima do óstracon, sugere o sono divino ou encantatório que arrebata, mas necessita de um complemento na frase (é verbo transitivo, como Page (PAGE: 1955, p. 38) argumenta, necessitando da expressão do objecto toma-

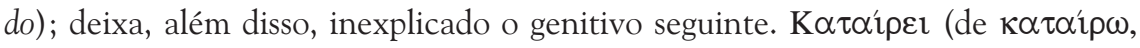
descer, abater-se sobre), por sua vez, adequa-se semanticamente ao contexto; esta seria, na verdade, a utilização mais antiga de um verbo que posteriormente se usará para referenciar a descida das aves e das abelhas; no entanto, em eólico surge regularmente com a variante $\alpha \dot{\varepsilon} p \rho \omega$. Já a forma proposta pela citação de

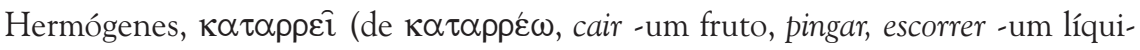
do, difundir-se), suspeita por não eólica, foi adoptada na variante do imperfeito por grande parte da crítica; a interpretação que sugere, configurando um complexo processo metafórico de associação (do insubstancial sono com a substância líquida que escorre gota a gota, dos sentidos visual, auditivo e táctil ${ }^{17}$ ), recria um clima mágico que escapa a racionalizações, onde a esfera local se amplia e impõe à interioridade psíquica - e torna a composição poética muita próxima das correntes artísticas mais modernas.

vv. 5-8 (comentário semântico): No lugar onde se misturam o colorido das rosas e o abafado da sombra, a configuração estética atinge o seu ponto mais alto. O espaço torna-se de três dimensões, com a imagem do incenso que se eleva e da água que escorre (para de seguida, nos vv.9-12, ganhar relevo a dimensão plana).

${ }^{16}$ Cfr. Il. $\Xi 358$ (Zeus vencido pelo poder de Hypnos, depois de seduzido pela esposa Hera), e Od. $\sigma$ 201(Atena adormecendo Penélope para a embelezar mais); além de Hesíodo (Theog. 798) e Píndaro (Pit. 1, 6 sqq.).

17 Note-se como a aliteração do v. 8 enfatiza ainda o processo de comunhão. 
Os extremos (escuridão e luz radiosa) parecem interligados, a fim de criar uma transição para a atmosfera do sonho, no qual se confundem sinestesicamente os sentidos (auditivo, visual, olfactivo e táctil). As folhas agitadas, que funcionam como o ponto final de um enquadramento composicional redutor (árvores-ramosflores-folhas), parecem representar, por fim, o sinal exterior da epifania, e o sono que alastra domina a topografia como um meio psíquico de manifestação da divindade.

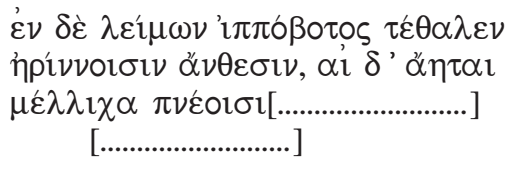

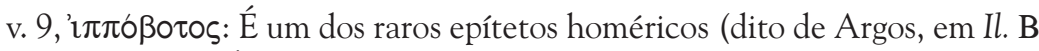
287, e, na negativa, de Ítaca, em Od. $\delta$ 606) usados por $\mathrm{Safo}^{18}$ (aqui com psilose); continua a apontar (obedecendo a uma intenção específica do poema) simbolicamente para a figura de Afrodite, cuja relação com os cavalos (e com a simbologia de libertação sexual que estes conotam) foi reconhecida desde a Antiguidade. Note-se que, em conformidade com a atitude de anonimato, ou atenuação presencial constante no poema, os cavalos não chegam a ver-se ou ouvir-se, existindo apenas como possibilidade no espaço de manifestação da divindade.

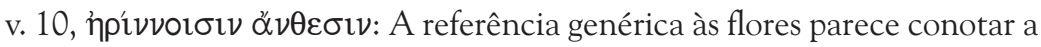
presença da deusa, que em Cnossos, já o vimos, era venerada como Afrodite Anteia; as insígnias da deusa continuam, portanto, a utilizar-se intencionalmente nos quadros descritos da natureza, enquanto suporte simbólico da presença imanente da divindade.

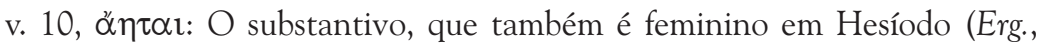

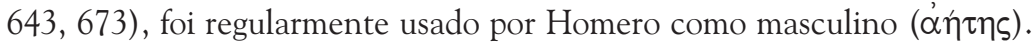

vv. 1-12 (comentário semântico): A descrição da espacialidade cumpre neste poema a mesma função que no fr. 1 surge atribuída à descrição da epifania e do poder da deusa: através das insígnias de culto e dos epítetos, e de um constante movimento da materialidade para a sugestão da imaterialidade, Afrodite é

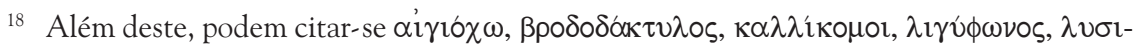
$\mu \dot{\varepsilon} \lambda \eta \varsigma, \tau \alpha \nu v \pi \tau \dot{\varepsilon} \rho v \gamma[$. 
introduzida, misteriosa e omnipresente, na descrição da paisagem; sem jamais empurrar para um primeiro plano a divindade, a descrição configura, pois, de forma indirecta e dinâmica, por meio da sua actuação na natureza, a omnipotência de Afrodite, e a sua omnipresença no lugar de revelação. Em consequência disso, a descrição serve de louvor permanente à divindade, e corporiza simbolicamente a imanência divina, servindo o fim artístico do poema (a interpelação a Afrodite): a apóstrofe explícita da deusa, no v. 13, surge assim orgânica e gradualmente preparada pelas indicações prévias dentro da topografia.

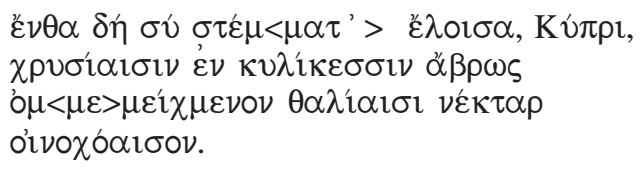

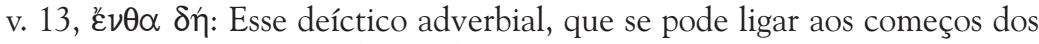

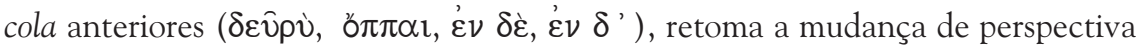

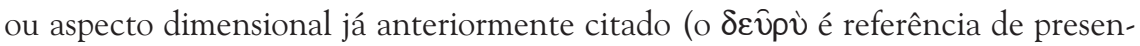
ça, o ع̌v $\theta \alpha$ de ausência): pode dizer-se que esta mudança se inscreve no mesmo esquema de acausalidade e discrição anterior; depois de preparar implicitamente na topografia a presença imanente da deusa, o eu poético interpelante retira-se discretamente do centro da dimensão poética, suplicando a Afrodite, como se estivesse de fora, que ocupe o lugar vazio, preenchendo o vácuo poético do campo de visão do poema; a última estrofe parece, pois, remeter para o acontecimento

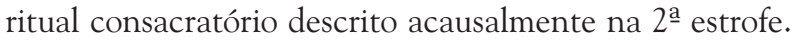

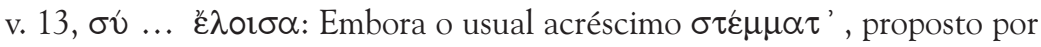
Norsa, permita uma boa sequência semântica, é alvo de fundamentadas suspeitas: grande parte da crítica não admite, na verdade, a probabilidade de que ele tivesse algum dia estado escrito no óstracon (Page, 1955, p. 39).

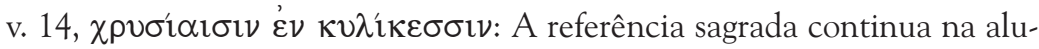
são às taças doiradas, que funcionam como objecto de culto; note-se particularmente que o adjectivo (aqui com alternância vocálica e desinência dialectal de dativo do plural) funcionava, na forma feminina, e na esfera dos deuses homéricos, como um epíteto distintivo de Afrodite (a doirada Afrodite), o que sublinha, nos elementos descritivos da composição, a continuada tendência para louvar o poder imanente e resplandecente da deusa na paisagem e nos objectos circundantes. 


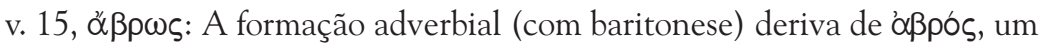
adjectivo que, não sendo homérico, é um dos favoritos de Safo (documentado em

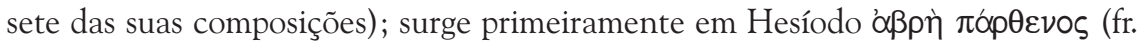
218 Rzach).

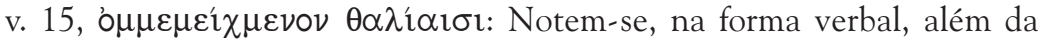
baritonese, as alternâncias vocálicas e consonântica, e na nominal de primeira declinação, a particular desinência de dativo plural. A tradução o puro néctar misturado com as festividades, proposta por Page, não é marcada pela habitual clareza sáfica; $\theta \alpha \lambda i \alpha \imath \_l$ pode ser interpretado como um dativo de fim (misturado para as festividades).

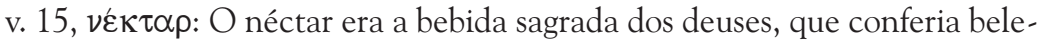
za e vitalidade aos imortais, imortalidade aos mortais, e incorruptibilidade aos mortos; alguns críticos interpretam-no como um elemento que confirma o transe hipnótico do $\kappa \hat{\omega} \mu \alpha$, e se apresenta como uma segunda imagem redundante para traduzir a acção poderosa da deusa; em consonância com outros momentos analisados do poema, o verso parece traduzir a passagem da substância à insubstancialidade (da materialidade vistosa das taças para a insubstancial festividade, e para o néctar imortal), que conforma o caminhar do finito para o infinito.

v. 16, o’voxóaıøov: O verbo, já utilizado em Homero, implicava regularmente (até pela sua etimologia) como complemento não o néctar, mas o vinho ${ }^{19}$. A irregular construção parece aqui enquadrar-se na leitura metafórica da prece enunciada: na sequência da atitude despersonalizante e acausal que vimos a relevar desde o início do poema, a própria divindade é convidada a protagonizar de forma dinâmica (como sacerdotisa) a consumação do ritual sagrado previamente preparado, realizando as habituais libações sacras; no entanto, enquanto ser imortal, ela será convidada a transmutar (pela sua natureza divina a que alude o néctar) o gesto humano (de encher as taças para as libações), realizando o processo místico de transformação do prazer finito (metonimicamente representado pela materialidade das taças onde costuma verter-se a bebida humana que é o vinho) em algo imortal e infinito (conotado com o néctar); pela prece e veneração, a celebrante anónima fará retornar à divindade o dom sagrado do amor tornado imortal, dádiva divina que deve ser recebida e retribuída.

19 No entanto, também uma vez na Ilíada (A 598) as libações são feitas com néctar. 
vv. 13-16 (comentário semântico): O começo da última estrofe resume pontualmente a topografia ( $\varepsilon v \theta \alpha \delta \eta$ ), estruturada na descrição segundo um princípio de seriação; com a interpelação à Cípria ( $\sigma u ́)$ retoma-se, num esquema compositivo simétrico, a epiclese subentendida do início (v. 1 e precedentes); como o texto está tão fragmentado, não podemos, porém, concluir sobre se esse regresso tem natureza anafórica, isto é, se é marcado por um verdadeiro eco verbal, ou se é mais livre, de natureza apenas semântica.

\subsection{Comentário estrutural}

Este poema corresponde formalmente à estruturação do tradicional poema clético (ou invocatório), em que a um primeiro momento (proposição, constituído por uma epiclese ou invocação à divindade), se seguia um desenvolvimento (a ع̌ $\phi \rho \alpha \sigma ı$, narração de uma história ilustrativa do poder divino, ou descrição dos seus efeitos) e uma conclusão (que regularmente retomava a situação inicial, reformulando a invocação e prece dirigidas à divindade). Neste aspecto formal, aproxima-se de outras composições sáficas, sobretudo do fragmento 1. Na verdade, quer este, quer o fragmento 1 começam com um momento de reflexão que se liga pessoalmente a Safo, contemporâneo e imediato. A este segue-se um desenvolvimento, ou demonstração, que de algum modo ilustra o início: à descrição do quadro topográfico que no fr. 2 ilustra a beleza e o poder imanente de Afrodite na natureza, corresponde, no poema 1 , a narração de uma experiência pessoal anterior, na qual Afrodite prestou socorro à interpelante subjugada por uma violência amorosa. Ambos terminam com um regresso à situação imediata ${ }^{20}$.

O elemento unificador das partes é sempre uma emoção pessoal. $\mathrm{O}$ esquema circular (a que François LASSERRE, 1948, p. 15, chama $\sigma \chi \hat{\eta} \mu \alpha \sigma \alpha \pi \phi ı$ เ aparece regularmente enfatizado pela similaridade verbal do início e do final do poema; no caso concreto do frag. 2, provavelmente destituído da sua estrofe inicial, a simetria continua a vislumbrar-se ao nível da epiclese (invocação), e particu-

20 A mesma estrutura tripartida, embora sem o carácter clético, aproxima-o ainda dos fragmentos 16 e 31. À reflexão inicial, segue-se, no fragmento 31, a descrição de um estado de paixão provocado pela visão do ser amado com o noivo; no 16, por sua vez, o exemplo mítico de Helena abandonando todas as suas riquezas, o marido e a filha para seguir Alexandre, o objecto do seu amor, ilustra o pensamento inicial de que nada é mais belo do que aquilo que o coração ama. À semelhança dos outros dois (fr. 1 e 2), também estes concluem retomando a situação inicial, de âmbito pessoal. 


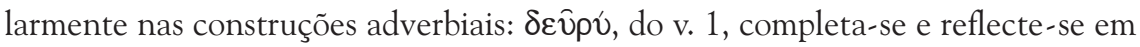
$\varepsilon ้ v \theta \alpha$, no v. 13, fazendo alusões recíprocas.

No entanto, os poemas representam diferentes tipos de experiência, e manifestam, por isso, diferenças de tom e estilo. No fragmento 2 não se apresentam argumentos retirados de anteriores dádivas ou favores recebidos, nem a alusão à urgência propiciada por um perigo iminente (como em 1); pelo contrário, o chamamento familiar, e o pedido de epifania ocorrem em doces palavras de confidência, como se Afrodite pudesse vir pelo seu próprio prazer, tentada pela beleza e alegria do local, que se apresentam como o motivo central da composição. A ênfase dada ao elemento topográfico não chega, no entanto, a ser estranha ou desajeitada, uma vez que a paisagem apresenta simbolicamente as características mais notórias da divindade invocada: assim, a descrição torna-se comparável à convencional descrição dos poderes da divindade usada neste tipo de hino; na verdade, a composição poética surge como a representação descritiva e imanente da divindade oferecida a essa mesma divindade para seu próprio prazer - e, naturalmente, para a propiciar.

Nenhum dos poemas considerados representa, além disso, estritamente falando, uma composição de culto (provavelmente nem um nem outro terão tido funcionalidade efectiva num ritual público): nem o tema chega verdadeiramente a ser o da devoção religiosa, traduzida no encarecimento dos atributos ou na narração das aventuras da divindade invocada, nem o apelo de epifania é motivado pela necessidade de ajuda à comunidade. Na verdade, trata-se de traduzir, numa manifestação profunda de emoção pessoal, o poder de uma experiência subjectiva de amor.

\section{Conclusões}

As análises lexical, semântica e estrutural feitas permitem-nos aceitar com alguma segurança a probabilidade de a última estrofe reconstituída a partir do óstracon ter encontrado correspondência numa primeira estrofe perdida, que conteria a invocação e prece à divindade.

Como Saake (SAAKE:1971, pp. 87 sqq.) nota, mesmo prescindindo do evidente princípio de tripartição do poema (epiclese, vv. 1a-1d/ topografia, vv. 112/ oração de súplica, vv. 13-16), pode descortinar-se ainda assim a estrutura do hino e os seus limites extremos através de outras adequações estruturais: a configuração das ideias espaciais, por exemplo, é aqui trabalhada através de delimitações detalhadas e inserções resumitivas. O primeiro âmbito local reconhecível, a 
partir da reconstituição da primeira linha do fragmento, $\rho \alpha \nu \circ \theta \varepsilon v \kappa \alpha \tau \imath o v$, na pos-

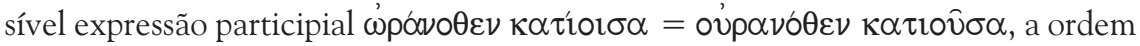
cósmica de Afrodite, surge, em simultâneo, como a espacialidade mais abrangente. A partir dela detalham-se, por progressivos estreitamentos de perspectiva - as unidades espaciais mais pequenas, primeiro Creta, e depois o espaço do bosque, o altar, os ramos das macieiras, a água que cai, as rosas, as folhas. Da ideia do lugar profundo e sombreado começa então a esboçar-se o recomeço de uma ampliação espacial inversamente proporcional: ao fumo que se eleva nos ares segue-se o prado espaçoso onde pastam (ou podem pastar) cavalos, e a imagem dos ventos que sopram volta a remeter para a espacialidade cósmica de Afrodite, dedutível no espaço da primeira estrofe.

Quanto à delimitação do final do poema, a indicação resumitiva do v. 13

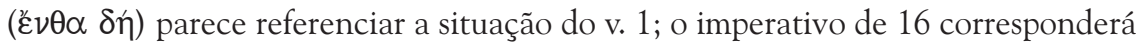
certamente também a uma forma analógica no início do poema; a estruturação simétrica deveria implicar além disso uma apóstrofe inicial correspondendo à do v. 13.

Em consonância com a circularidade espacial apresentam-se ainda os dois momentos da temporalidade do poema: a descida da divindade e a súplica que lhe é feita formam os pontos limites de um enquadramento definido. $O$ primeiro alude, por meio da cena dos altares fumegantes, ao pretexto ritual de base, ao passo que o segundo, por meio do pensamento da alegria no convívio, eleva a situação imanente do poema a uma festa na esfera de Afrodite.

Uma vez que o que nos resta evidencia, com sua natureza circular, um necessário carácter unitário, e que a última estrofe cumpre os requisitos necessários à conclusão de um hino invocatório, julgamos inútil, e afuncional, a expectativa de uma continuação para o poema. Mais: tentarmos acrescentar, inspirados pelo testemunho de Ateneu, uma alusão às jovens de Safo, depois do v. 16, é pôr em causa a atitude básica constante deste poema- a de deixar o mais possível de fora a configuração pessoal, procurando sempre (ainda que à custa de alguma acausalidade) um reservado anonimato, uma discreta mediatez. Nenhum motivo aponta, na verdade, para lá da fronteira do último verso transmitido. O poema surge como um todo orgânico, fechado, absolutamente coerente nos pormenores e na temática.

O poema parece configurar, dentro dos esquemas temáticos habituais em Safo, um apelo a Afrodite. Não estranha, portanto (como sublinhou uma facção da crítica), que muitas das referências utilizadas pertençam tradicionalmente ao mundo de conotações amorosas e/ou eróticas mais ou menos evidentes, e mais ou 
menos glosadas, desde sempre, em todas as manifestações artísticas: os bosques, as árvores (particularmente as macieiras), as águas, as flores, os cavalos, as brisas, o ouro e as taças... De notar é que esse apelo amoroso (ou erótico) se realiza metafórica e enigmaticamente pela vivência das belezas mais simples e íntimas da natureza: os brilhos, as cores, as sombras, os silêncios e os murmúrios, as raízes e os movimentos, as profundidades e as alturas. Em Safo, a natureza é - ela mesma uma emoção mística, e todas as turbações do espírito são o subtil palpitar da natureza na secreta esfera do íntimo.

Por isso soa tão natural e tão simples este enigma de uma paisagem sem lugar nem tempo ${ }^{21}$, servindo de pretexto a uma comunicação secreta (e quase inexplicável, fruto de um transe) com a divindade, onde se mesclam indissoluvelmente o finito das coisas sensíveis e o ilimitado da sua mágica natureza imperecível.

Sem saber como, sem conseguir explicá-lo, o leitor percebe, por um quase sortilégio, que esse jardim secreto, ensombrado de rosas e beijado pelo murmúrio de águas frescas - onde ele é também convidado a entrar, e a gozar da presença imanente de Afrodite - mais não é que o jardim encantado da obra poética de Safo.

\section{REFERÊNCIAS Bibliográficas}

BERGK, T. 1882: Poetae Lyrici Graeci, Leipzig, $1882^{4}$.

Bonnard, A. 1948: La poésie de Sapho. Etude et Traduction, Mermod, Lausanne, 1948.

Burnett, A. P., 1983: Three Archaic Poets: Archilocus, Alcaeus, Sappho, London, Duckworth, 1983.

21 A paisagem descrita é extemporânea: embora se lhe chame poema da Primavera (estando certamente este título inspirado pelo termo ñ formularmente desde Homero, Il. B 89; Hesíodo, Theog.279 e Erg.75; e nos Hinos, cfr. H. Dem. 401), ele mistura elementos paisagísticos de vários períodos diferentes- às flores de Primavera sucedem-se o florir das rosas (do início do Verão) e as maçãs (que pertencem ao final da mesma estação, embora a floração suceda na Primavera); a estas associam-se inúmeras discussões sobre o momento da poesia (manhã, tarde, ou noite) que apenas acham uma resposta plausível- o poema não descreve um momento específico do dia, nem sequer do calendário, como parece não reflectir uma localização geográfica específica. 
Campbell, D. A., 1967: Greek Lyrik Poetry, A Selection of Early Greek Lyric, Elegiac and Iambic Poetry, London, St. Martin's Press, 1967.

. 1982: Greek Lyrik, I- Sappho and Alcaeus, Loeb Classical Lybrary, 1982 (reimp. 1990).

. 1983: The Golden Lyre. The Themes of Greek Lyric Poets, London, Duckworth, 1983.

Colonna, A. 1958: LAntica Lirica Greca, Firenze, 1958, $1963^{2}$.

DienL, E., 1936: Anthologia Lyrica Graeca, vol I, Leipzig, 1936.

FRÄNKEL, H., 1962: Dichtung und Philosophie des fruhen Griechentums, 1962, (Early Greek Poetry and Philosophy, transl. by M. Hadas and J. Willis, Oxford, 1975).

Galiano, M. F., 1958: Safo, Madrid, Cuadernos de la Fundacion Pastor, 1958.

Gallavoti, C. 1942: "L'Ode Saffica dell' óstracon fiorentino" Studi Italiani di Filologia Clasica 18, 1942. . 1954: Saffo e Alceo I, 1954 (Saffo), 1962³.

KIRKWOOD, G. M. 1974: Early Greek Monody, The History of a Poetic Type, CUP, London, 1974.

Lanata, G. 1959: "L' óstracon Fiorentino con versi di Saffo", Studi Italiani di Filologia Clasica 31, 1959, 64-90.

Lasserre, F., 1948: "Un noveau fragment d' Archiloque”, Mus. Helv. 5, 1948, pp. 15 sqq.

Lesky, A., 1957: História da Literatura Grega, Lisboa, 1995 (trad. do original Geschichte der Griechischen Literatur, 1957).

Lobel, E. and Page, D., 1955: Poetarum Lesbiorum Fragmenta, Oxford, Clarendon Press, 19632.

Martin, V. 1947: "La poésie lyrique et la poésie dramatique dans les découvertes papyrologiques", Mus.Helv. 4, 1947, 74-100.

MatThiessen, F. O. 1957: "Das Gedicht Sapphos auf der Scherbe", Gymnasium 64, 1957, 554 sqq..

NorSA, M. 1937: "Versi di Saffo in un Óstracon del sec. II a. C.", Annali della R. Scuola Normale Superiore Universitaria di Pisa, Lett. e Stor. e Fil., ser. 2, 6, 1937, fasc. 1-2, pp. 8-15.

Page, D. L., 1955: Sappho and Alcaeus, An Introduction to the Study of Ancient Lesbian Poetry, Oxford, Clarendon Press, 1955.

. 1962: Poetae Melici Graeci, Oxford, 1962. 
. 1968: Lyrica Graeca Selecta, Oxford, 1968.

. 1974: Supplementum Lyricis Graecis, Oxford, 1974.

. 1975: Epigrammata Graeca, Oxford, 1975.

Pereira da Rocha, M. H. 1959: Hélade, Antologia de Cultura Grega, Coimbra, 19958. . 1964: Estudos de História da Cultura Clássica, I Vol. - Cultura Grega, Lisboa, 1964, 20039.

Pfeiffer, R. 1937: "Vier Sappho-Strophen auf einem ptolemaischen Óstracon", Philologus 92, 1937, pp. 117 sqq..

Rivier, A., 1948: "Sur un vers-clé de Sappho", Mus. Helv., 5, 1948, pp. 227-39.

SAAKE, $\mathrm{H}$.

. 1971: Zur Kunst Sapphos. Motiv-analytische und Kompositiontechnische Interpretationen, München, 1971.

. 1972: Sapphostudien, München, 1972.

Schadewald, W. 1950: Sappho,Potsdam, 1950.

Schubart, W. 1938: "Bemerkungen zu Sappho", Hermes 73, 1938, pp. 297 sqq.. . 1948: "Zu mehreren Gedichten der Sappho", Philologus 98, 1948, 312 sqq..

Setti, A., 1943: "Il frammento Saffico dell' óstracon fiorentino", Studiltaliani di Filologia Clasica, 19, 1943, 125 sqq..

Siegmann, E. 1941: “Anmerkungen zum Sappho-Óstracon”, Hermes, 76, 1941, 417 22.

SNell, B., 1955: Griechische Metrik, 1955.

Theander, C. 1937: "Zum neuesten Sappho- Fund", Philologus 101, 1937, 465 sqq.. Theiler, W. e Mühll, von der P., 1946: "Das Sapphogedicht auf der Scherbe", Mus.Helv. 3, 1946, 22-5.

Treu, M. 1954: Sappho, Munich, 1954', $1968^{4}$.

_. 1966: "Neues über Sappho und Alkaios (pap. Ox 2506)", Quad. Urb. 2, 1966, 9 sqq..

TurYn, A. 1929: Studia Saphica, Eos Suppl. 6, 1929. . 1942: "The Sapphic óstracon,", TAPhA 73, pp. 308 sqq.. 
PINTO, Ana Paula. Sappho, or the fragmentary beauty.

ABSTRACT: Sappho and the fragment 2 L.P. The irregularity of the transmission process as the basis for the problems in delimiting, fixing and interpreting the text. Morphosyntactic, dialectal, semantic and structural analysis. An attempt at interpreting the poetic message.

KEYWORDS: Greek literature; Sappho. 